Quim. Nova, Vol. 34, No. 5, 748-752, 2011

\title{
OCORRÊNCIA DE AGROTÓXICOS EM ÁGUAS SUBTERRÂNEAS DE ÁREAS ADJACENTES A LAVOURAS DE ARROZ IRRIGADO
}

\author{
Diecson Ruy Orsolin da Silva*, Luis Antonio de Avila, Dirceu Agostinetto e Angela Da Cas Bundt \\ Departamento de Fitossanidade, Universidade Federal de Pelotas, Campus de Capão do Leão, 96010-900 Pelotas - RS, Brasil \\ Ednei Gilberto Primel e Sergiane Souza Caldas \\ Escola de Química e Alimentos, Universidade Federal do Rio Grande, 96201-900 Rio Grande - RS, Brasil
}

Recebido em 19/3/10; aceito em 22/11/10; publicado na web em 18/2/11

\begin{abstract}
PESTICIDE OCCURRENCE IN GROUNDWATER NEAR IRRIGATED RICE FIELDS. The objective this study was to monitor pesticide residues in groundwater at three different times and in seven regions producing rice in southern Brazil, in the 2007/08 season. Imazethapyr and fipronil were found in all regions studied. All groundwater samples from the Planície Costeira Interna to Lagoa dos Patos and Santa Catarina contained at least one pesticide. The lowest number of contaminated samples were detected in the Southern region. The highest frequency of contaminated samples was found after drainage of the rice fields. Only fipronil exceeded limits of potability, in $27 \%$ of samples, according European Community criteria.
\end{abstract}

Keywords: contamination; environmental fate; residues.

\section{INTRODUÇÃO}

No Rio Grande do Sul (RS) e em Santa Catarina (SC), o arroz irrigado é uma das principais atividades agrícolas e econômicas, com área total nos dois estados de aproximadamente 1,2 milhões de hectares. ${ }^{1,2} \mathrm{O}$ sistema atual de produção de arroz irrigado, demanda uma ampla utilização de agrotóxicos, sendo recomendados para a cultura 29 herbicidas, 12 inseticidas e 8 fungicidas. $^{3}$

Ao longo das últimas décadas, com o aumento de área cultivada e do uso de agrotóxicos, intensificou-se a preocupação com o destino destes no ambiente. Os mananciais hídricos, tanto superficiais quanto subterrâneos, estão expostos aos agrotóxicos aplicados em áreas agrícolas e não agrícolas. Nos cultivos de monoculturas, como, normalmente, ocorre com a cultura do arroz, a contaminação das águas subterrâneas por agrotóxicos ocorre de forma difusa, o que a torna mais difícil de ser identificada e controlada. ${ }^{4}$

$\mathrm{O}$ risco dos agrotóxicos atingirem os mananciais hídricos subterrâneos pode ser determinado pelo transporte descendente, o qual é dependente de fatores climáticos, propriedades do solo, práticas de manejo das lavouras, profundidade do manancial e propriedades físico-químicas dos agrotóxicos. ${ }^{4-6}$

Estudos de monitoramento, em países europeus, constataram contaminação de águas subterrâneas por herbicidas, após mais de uma década de proibição de uso. ${ }^{7,8}$ A tendência dos agrotóxicos estarem presentes em águas subterrâneas é a sua acumulação, uma vez que esse ambiente é considerado recalcitrante, ou seja, não existem condições favoráveis para a degradação das moléculas em função de baixas temperaturas, falta de oxigênio, baixa atividade dos micro-organismos e ausência de luminosidade. Dentre os problemas de contaminação das águas subterrâneas por agrotóxicos destaca-se o fato de ser utilizada para consumo humano, o que poderá acarretar sérios problemas de saúde pública.

No Brasil, estão estabelecidos pela resolução do CONAMA $n^{\circ}$ 396/2008 e a Portaria do MS n ${ }^{\circ}$ 518/2004 padrões de potabilidade da

*e-mail: diecsonros@hotmail.com água destinada ao consumo humano, embora ambas as legislações vigentes não contemplem todos os agrotóxicos recomendados na orizicultura, e os limites máximos admitidos dependem do agrotóxico utilizado. Já a Comunidade Europeia estabeleceu padrões de potabilidade para águas destinadas ao consumo humano de $0,1 \mu \mathrm{g} \mathrm{L} \mathrm{L}^{-1}$ para um e $0,5 \mu \mathrm{g} \mathrm{L} \mathrm{L}^{-1}$ para a soma de todos os agrotóxicos presentes, incluindo seus metabólitos. ${ }^{9}$

No Brasil, foram realizados estudos visando avaliar a presença de agrotóxicos em águas subterrâneas próximas a lavouras de algodão no estado do Mato Grasso (MT), fumo e outras atividades agrícolas no RS, ${ }^{10-12}$ entretanto não existem estudos que quantifiquem a presença de agrotóxicos em águas subterrâneas do RS em regiões adjacentes às lavouras de arroz irrigado.

Em vista disto, foi realizado este estudo com o objetivo de avaliar a ocorrência de resíduos de agrotóxicos em águas subterrâneas, comumente utilizada para consumo humano, na estação de cultivo 2007/08, em três diferentes épocas e em sete regiões produtoras de arroz irrigado nos estados do Rio Grande do Sul e Santa Catarina.

\section{PARTE EXPERIMENTAL}

\section{Amostragem}

O estudo foi realizado em seis regiões produtoras de arroz do RS e uma em SC. Dentro de cada região foram selecionados 3 municípios, baseados na maior área cultivada com arroz e na sua posição geográfica. As regiões, o local, a profundidade do poço e a posição geográfica dos pontos de amostragens são apresentados na Tabela 1 .

As amostras de água foram coletadas em três épocas, sendo a primeira anterior ao cultivo das lavouras orizícolas (entre os dias 24/10/07 a 8/11/07), a segunda durante o desenvolvimento da cultura (entre os dias 17/12/07 a 03/01/2008) e a terceira após a drenagem da água das lavouras para colheita (entre os dias 25/03/08 a 05/04/08).

As amostras de águas de origem subterrânea foram coletadas de reservatórios residenciais ou diretamente de poços. Após a coleta, as amostras de água foram armazenadas em recipientes de vidro de cor 
Tabela 1. Região, local, profundidade e posição geográfica dos poços subterrâneos monitorados nas regiões orizícolas do Sul do Brasil na safra 2007/08

\begin{tabular}{|c|c|c|c|c|}
\hline \multirow[t]{2}{*}{ Região } & \multirow[t]{2}{*}{ Local } & \multirow{2}{*}{$\begin{array}{l}\text { Profundidade } \\
\text { (m) }\end{array}$} & \multicolumn{2}{|c|}{ Posição Geográfica } \\
\hline & & & $\begin{array}{l}\text { Latitude } \\
\text { (Sul) }\end{array}$ & $\begin{array}{c}\text { Longitude } \\
\text { (Oeste) }\end{array}$ \\
\hline \multirow{3}{*}{$\begin{array}{l}\text { Fronteira Oeste } \\
\text { (RS) }\end{array}$} & Uruguaiana & 40 & $29^{\circ} 39,207^{\prime}$ & $56^{\circ} 53,489^{\prime}$ \\
\hline & Itaqui & 12 & $29^{\circ} 07,196^{\prime}$ & $56^{\circ} 32,579^{\prime}$ \\
\hline & Alegrete & 50 & $29^{\circ} 43,459$ & $56^{\circ} 03,301^{\prime}$ \\
\hline \multirow{3}{*}{$\begin{array}{l}\text { Campanha } \\
\text { (RS) }\end{array}$} & Rosário do Sul & 60 & $30^{\circ} 17,363^{\prime}$ & $54^{\circ} 53,710^{\prime}$ \\
\hline & São Gabriel & 60 & $30^{\circ} 22,598^{\prime}$ & $54^{\circ} 21,371^{\prime}$ \\
\hline & Dom Pedrito & 20 & $30^{\circ} 56,563^{\prime}$ & $54^{\circ} 43,451^{\prime}$ \\
\hline \multirow{3}{*}{$\begin{array}{l}\text { Sul } \\
\text { (RS) }\end{array}$} & Arroio Grande & 10 & $32^{\circ} 15,243^{\prime}$ & $53^{\circ} 04,759^{\prime}$ \\
\hline & Jaguarão & 11 & $32^{\circ} 27,652^{\prime}$ & $53^{\circ} 27,141^{\prime}$ \\
\hline & Santa Vitória do Palmar & 18 & $32^{\circ} 56,147^{\prime}$ & $52^{\circ} 41,676^{\prime}$ \\
\hline \multirow{3}{*}{$\begin{array}{l}\text { Planície Costeira Interna à } \\
\text { Laguna dos Patos (RS) }\end{array}$} & Arambaré & 6 & $30^{\circ} 59,553^{\prime}$ & $51^{\circ} 29,718^{\prime}$ \\
\hline & Tapes & S.I. ${ }^{1}$ & $30^{\circ} 43,037^{\prime}$ & $51^{\circ} 25,979^{\prime}$ \\
\hline & Barra do Ribeiro & 9 & $30^{\circ} 21,680^{\prime}$ & $51^{\circ} 16,309^{\prime}$ \\
\hline \multirow{3}{*}{$\begin{array}{l}\text { Planície Costeira Externa à } \\
\text { Laguna dos Patos (RS) }\end{array}$} & Viamão & 64 & $29^{\circ} 57,696^{\prime}$ & $51^{\circ} 00,119^{\prime}$ \\
\hline & Capivari do Sul & 40 & $30^{\circ} 08,611^{\prime}$ & $50^{\circ} 32,853^{\prime}$ \\
\hline & Santo Antonio da Patrulha & 29 & $29^{\circ} 53,519^{\prime}$ & $50^{\circ} 25,630^{\prime}$ \\
\hline \multirow[t]{3}{*}{ Depressão Central (RS) } & Restinga seca & 9 & $29^{\circ} 55,546^{\prime}$ & $53^{\circ} 24,979^{\prime}$ \\
\hline & Cachoeira do Sul & 8 & $30^{\circ} 03,761^{\prime}$ & $52^{\circ} 53,658^{\prime}$ \\
\hline & Santa Maria/São Sepé & 60 & $28^{\circ} 56,238^{\prime}$ & $53^{\circ} 42,643^{\prime}$ \\
\hline \multirow{3}{*}{$\begin{array}{l}\text { Santa Catarina } \\
\text { - Região Sul -b (SC) }\end{array}$} & Meleiro - Rio Manuel Alves & 6 & $28^{\circ} 52,608^{\prime}$ & $49^{\circ} 32,141^{\prime}$ \\
\hline & Meleiro - Rio Itoupava & S.I. & $28^{\circ} 54,975$ & $49^{\circ} 32,012^{\prime}$ \\
\hline & Araranguá & 3,5 & $28^{\circ} 53,967^{\prime}$ & $49^{\circ} 27,580^{\prime}$ \\
\hline
\end{tabular}

${ }^{1}$ Sem Informações.

âmbar, com capacidade de $1 \mathrm{~L}$, previamente identificadas e acondicionadas em caixas térmicas contendo gelo. Antes de cada coleta, a garrafa coletora e o recipiente para armazenamento da amostra eram lavados com água do próprio local de coleta.

\section{Extração e determinação dos agrotóxicos}

As extrações e determinações dos agrotóxicos foram realizadas de acordo com o descrito em Demoliner et al. ${ }^{13}$

As amostras foram acidificadas a pH 3,0 com ácido fosfórico 1:1 (v/v), filtradas a vácuo e pré-concentradas nos cartuchos de C18ec no mesmo dia da coleta. A etapa de pré-concentração das amostras e extração dos analitos foi realizada utilizando a técnica de SPE com cartuchos Chromabond C18ec de $500 \mathrm{mg}$. Foram passados $250 \mathrm{~mL}$ de amostra pelos cartuchos e a eluição foi realizada com $1 \mathrm{~mL}$ de metanol, resultando em um fator de pré-concentração de 250 vezes. Todas as amostras foram extraídas em triplicata e injetadas três vezes cada replicata no cromatógrafo $(n=9)$.

As amostras foram analisadas utilizando-se cromatógrafo a líquido Alliance Separations modelo 2695 Waters (Milford, MA, USA) equipado com amostrador automático, bomba quaternária, sistema de desgaseificação, detector MS, Micromass ${ }^{\circledR}$ Quatro Micro ${ }^{\text {TM }}$ API Waters com fonte API, utilizando o modo de ionização por electrospray, sistema de aquisição de dados através do software Masslynx 4.0 Waters e coluna analítica XTerra ${ }^{\circledR}$ MS C18 3,5 $\mu \mathrm{m} 144 \AA$ A $(50 \times 3$ mm d.i. $)$.

A eluição foi feita no modo isocrático com $46 \%$ de água ultrapura contendo $0,1 \%$ ácido fórmico, $24 \%$ de acetonitrila com $0,1 \%$ ácido fórmico e $30 \%$ de metanol, em uma vazão de $0,5 \mathrm{~mL} \mathrm{~min}^{-1}$, resultando em um tempo de análise de $10 \mathrm{~min}$. O volume de injeção das amostras foi de $20 \mu \mathrm{L}$. Os limites de detecção do método variaram entre 2,0-40,0 ng $\mathrm{L}^{-1}$, enquanto para os limites de quantificação a variação foi de 4,0-100,0 $\mathrm{ng} \mathrm{L}^{-1}$.

\section{Estudo de ocorrência dos agrotóxicos}

Os agrotóxicos estudados foram os herbicidas clomazone, imazapic, imazethapyr, penoxsulam e quinclorac; os inseticidas 3-hidroxi-carbofuran (metabólito do carbofuran), carbofuran e fipronil e o fungicida tebuconazole. Os agrotóxicos encontram-se na Tabela 2, bem como informações quanto à solubilidade em água, coeficiente de adsorção ao carbono orgânico do solo $\left(\mathrm{k}_{\mathrm{oc}}\right)$, meia-vida em solo $\left(\mathrm{t}_{1 / 2}\right)$, coeficiente de partição octanol-água $\left(\mathrm{k}_{\mathrm{ow}}\right)$ e índice GUS (Groundwater Ubiquity Score) dado pela equação GUS $=\log$ $\left(\mathrm{t}_{1 / 2}\right.$ solo $) \mathrm{x}\left(4-\log \mathrm{k}_{\mathrm{oc}}\right)$, que indica o potencial dos agrotóxicos em lixiviar e contaminar águas subterrâneas, e se baseia na meia-vida em solo e no coeficiente de adsorção a matéria orgânica do solo. Quando o composto apresentar GUS $<1,8$ é improvável que ocorra lixiviação; quando apresentar $1,8<$ GUS $<2,8$ se encontra na zona de transição e, GUS > 2,8 os compostos provavelmente lixiviam. ${ }^{6}$ A partir dos resultados obtidos, foram calculadas as frequências das amostras contaminadas com agrotóxico (acima do limite de detecção do método) e a concentração máxima de cada agrotóxico em cada época de avaliação. A concentração média e a frequência de detecção foram calculadas para cada agrotóxico em cada local de coleta.

\section{RESULTADOS E DISCUSSÃO}

Na média de todo o período e de todos os locais estudados, os agrotóxicos em maiores frequências em águas subterrâneas foram fipronil, imazethapyr, clomazone, imazapic e quinclorac, detectados em $87,42,23,19$ e $2 \%$ do total das amostras monitoradas, respectivamente (Tabela 3 ).

Não foram encontrados resíduos de penoxsulam, carbofuran, 3-hidroxi-carbofuran e tebuconazole nas amostras de águas subterrâneas. A não ocorrência de penoxsulam em águas subterrâneas pode 
Tabela 2. Propriedades físico-químicas dos agrotóxicos e avaliação do risco de contaminação de águas subterrâneas adotando critério de GUS

\begin{tabular}{|c|c|c|c|c|c|c|c|}
\hline Agrotóxicos & $\begin{array}{c}\text { Solubilidade } \\
\left(\mathrm{mg} \mathrm{L}^{-1}\right)\end{array}$ & $\begin{array}{c}\mathrm{K}_{\mathrm{oc}} \\
\left(\mathrm{mL} \mathrm{g}^{-1}\right)\end{array}$ & $\begin{array}{c}\mathrm{t}_{1 / 2} \text { solo } \\
\text { (dias) }\end{array}$ & $\mathrm{K}_{\mathrm{ow}}$ & GUS $^{1}$ & $\begin{array}{c}\text { LOD } \\
\left(\mathrm{ng} \mathrm{L}^{-1}\right)\end{array}$ & $\begin{array}{c}\mathrm{LOQ} \\
\left(\mathrm{ng} \mathrm{L}^{-1}\right) \\
\end{array}$ \\
\hline$\overline{\text { Clomazone }(\mathrm{H})^{2}}$ & 1100 & 300 & 24 & 346,7369 & 2,10 (I) & 2 & 20 \\
\hline Imazapic $(\mathrm{H})$ & 2200 & 206 & 120 & 0,01 & $3,50(\mathrm{X})$ & 4 & 40 \\
\hline Imazethapyr (H) & 1400 & 53 & 60 & 30,90295 & $4,04(\mathrm{X})$ & 4 & 40 \\
\hline Penoxsulam $(\mathrm{H})$ & 410 & 104 & 46 & 0,442588 & $3,29(\mathrm{X})$ & 40 & 100 \\
\hline Quinclorac (H) & 62 & 36 & 31 & 0,070795 & $3,64(X)$ & 40 & 100 \\
\hline 3-hidroxi-carbofuran ${ }^{3}$ & -4 & - & - & - & - & 20 & 40 \\
\hline Carbofuran (I) & 351 & 29,4 & 138 & 30,90295 & $5,41(\mathrm{X})$ & 2 & 20 \\
\hline Fipronil (I) & 2,4 & 803 & 140 & 10232,9 & 2,35 (I) & 2 & 4 \\
\hline Tebuconazole $(\mathrm{F})$ & 36 & 1000 & 100 & 5011,872 & $2,00(\mathrm{I})$ & 2 & 4 \\
\hline
\end{tabular}

${ }^{1}$ (I) lixiviação intermediária, (X) provavelmente sofra lixiviação; ${ }^{2}$ Herbicida (H), Inseticida (I) e Fungicida (F); ${ }^{3}$ Metabólito do carbofuran; ${ }^{4}$ Propriedades físico-químicas não disponíveis.

estar associada ao fato do produto ter rápida dissipação em condições de solo anaeróbicas e apresentar meia-vida por fotólise relativamente curta, cerca de 2,1 h. ${ }^{14}$ Além destes fatores, esse herbicida é utilizado em baixa quantidade por área e em área relativamente menor de cultivo. Já o inseticida carbofuran tem a dissipação via hidrólise aumentada na medida em que o $\mathrm{pH}$ do meio se eleva, ${ }^{15}$ fator muito comum em solos inundados. Por sua vez, o fungicida tebuconazole possui capacidade intermediária de lixiviar para camadas de solo mais profundas, segundo critérios de GUS. Associado a isso, a baixa utilização de fungicidas na cultura do arroz irrigado, comparada com as demais classes de agrotóxicos, coopera para a não ocorrência deste no compartimento subterrâneo.

Dentre as épocas amostradas, para fipronil, imazethapyr e clomazone, a maior ocorrência foi na época após a drenagem das lavouras ( $3^{\mathrm{a}}$ época). Apesar de fipronil ter sido encontrado em grande frequência, possui lixiviação intermediária, segundo critérios de GUS (Tabela 2), o valor de $\mathrm{K}_{\mathrm{oc}}$ de fipronil de 803 é indicativo de moderada mobilidade no solo. Em baixas concentrações fipronil tem maior afinidade com a fase aquosa do solo, podendo assim ser mais facilmente transportado para camadas mais profundas. ${ }^{16}$

O herbicida imazethapyr possui comportamento no solo dependente do $\mathrm{pH}$, sendo que em $\mathrm{pH}$ próximo ao alcalino o herbicida tende estar na forma dissociada, o que aumenta sua mobilidade no solo, associado à meia-vida de 60 dias e baixa degradação microbiana em condições de anaerobiose ${ }^{14}$ este herbicida tem a tendência de lixiviar para camadas mais profundas do perfil do solo.

Clomazone comporta-se como herbicida não iônico, deste modo, sua mobilidade não responde à variação de $\mathrm{pH}$. Com relação à dis- sipação, adsorção e translocação de clomazone em diferentes solos, verificou-se correlação negativa com a CTC, carbono orgânico, argila e Kd, sugerindo que a lixiviação é menor quanto maiores forem os valores desses parâmetros, e sob condições de chuva simulada (200 $\mathrm{mm}$ ), apenas $4,2 \%$ do clomazone aplicado na superfície do solo ultrapassou $20 \mathrm{~cm}$ de profundidade. ${ }^{17}$

Para os herbicidas imazapic e quinclorac, as maiores frequências foram observadas durante o cultivo do arroz, ocorrendo, respectivamente, em 29 e $5 \%$ das amostras (Tabela 3). Imazapic possui potencial para contaminar águas subterrâneas por lixiviação (critérios de GUS), constatando-se meia-vida em solo de 120 dias, contudo quando em condições de anaerobiose não ocorre degradação do produto. ${ }^{14} \mathrm{O}$ quinclorac, comparado com os herbicidas analisados, apresenta baixa solubilidade em água (62 mg L $\left.\mathrm{L}^{-1}\right)$ e baixa sorção com o carbono orgânico do solo, o que pode influenciar a lixiviação desse herbicida.

Para todos os agrotóxicos encontrados, apenas quinclorac não ocorreu em todas as épocas monitoradas. Um dos fatores que explicam a baixa ocorrência deste herbicida em águas subterrâneas pode estar ligado à mobilidade em solo, uma vez que quase que a totalidade do herbicida não ultrapassa uma camada de $30 \mathrm{~cm}$ de solo em condições de lavouras de arroz inundado. ${ }^{18}$ Além disso, quinclorac é utilizado em menor percentagem nas áreas cultivadas com arroz irrigado.

$\mathrm{Na}$ comparação entre as épocas monitoradas, observou-se que $81 \%$ das amostras continham ao menos um agrotóxico em águas subterrâneas na época anterior ao cultivo de arroz, $86 \%$ durante o cultivo do arroz, e na época após a drenagem das lavouras todas as amostras de águas subterrâneas continham a presença de ao menos um agrotóxico (Tabela 3). Cabe destacar ainda que fipronil apresentou

Tabela 3. Frequência de detecção de agrotóxicos (\%) e concentração máxima (ng L $\left.{ }^{-1}\right)$ de agrotóxicos nas águas subterrâneas, na média de três épocas e nas sete regiões orizícolas do sul do Brasil na safra 2007/08

\begin{tabular}{|c|c|c|c|c|c|c|c|}
\hline \multirow[t]{2}{*}{ Agrotóxicos } & \multicolumn{4}{|c|}{ Frequência (\%) } & \multicolumn{3}{|c|}{$\begin{array}{l}\text { Concentração máxima } \\
\left(\text { ng L L }^{-1}\right) \pm \mathrm{CV}(\%)^{*}\end{array}$} \\
\hline & $1^{\mathrm{a}}$ época ${ }^{1}$ & $2^{\mathrm{a}}$ época & $3^{\mathrm{a}}$ época & Total & $1^{\mathrm{a}}$ época & $2^{\mathrm{a}}$ época & $3^{\mathrm{a}}$ época \\
\hline Clomazone & 5 & 10 & 55 & 23 & $<\mathrm{LOQ}^{3}$ & $13 \pm 14$ & $32 \pm 8$ \\
\hline Imazapic & 19 & 29 & 10 & 19 & $<\mathrm{LOQ}$ & $<$ LOQ & $14 \pm 9$ \\
\hline Imazethapyr & 24 & 10 & 95 & 42 & $<\mathrm{LOQ}$ & $<$ LOQ & $57 \pm 7$ \\
\hline Penoxsulam & nd & nd & nd & nd & nd & nd & nd \\
\hline Quinclorac & $\mathrm{nd}^{2}$ & 5 & nd & 2 & nd & $60 \pm 5$ & nd \\
\hline 3-hidroxi-carbofuran ${ }^{4}$ & nd & nd & nd & nd & nd & nd & nd \\
\hline Carbofuran & nd & nd & nd & nd & nd & nd & nd \\
\hline Fipronil & 76 & 86 & 100 & 87 & $87 \pm 6$ & $320 \pm 3$ & $3440 \pm 5$ \\
\hline Tebuconazole & nd & nd & nd & nd & nd & nd & nd \\
\hline Ao menos um agrotóxico & 81 & 86 & 100 & 89 & - & - & - \\
\hline
\end{tabular}

${ }^{1} 1^{\mathrm{a}}$ época: anterior ao cultivo do arroz, $2^{\mathrm{a}}$ época: durante o cultivo do arroz, $3^{\mathrm{a}}$ época: após a drenagem das lavouras; ${ }^{2}$ Não detectado; ${ }^{3}$ Menor que o limite de quantificação; ${ }^{4}$ Metabólito do carbofuran. * Coeficiente de variação percentual (CV \%). 
frequências que variaram de 76 a 100\% nas três épocas monitoradas.

As concentrações dos agrotóxicos foram maiores na época após a drenagem das lavouras para fipronil, clomazone, imazethapyr e imazapic (Tabela 2). Para quinclorac, a maior concentração foi durante o cultivo do arroz. Nas épocas durante o cultivo e após a drenagem das lavouras, apenas para fipronil constatou-se concentrações máximas acima do limite dos padrões de potabilidade da água proposto pela Comunidade Europeia que é de $0,1 \mu \mathrm{g} \mathrm{L}^{-1}$, sendo que concentrações acima desse valor foram verificadas em $27 \%$ das amostras (dado não apresentado).

Foram detectados resíduos de agrotóxicos em todas as regiões monitoradas, no entanto, não foram detectadas as presenças de penoxsulam, carbofuran, 3-hidroxi-carbofuran e tebuconazole (Tabela 4). Clomazone foi detectado em cinco regiões, exceto na Depressão Central e Planície Interna à Laguna dos Patos, em que as maiores frequências foram nas regiões da Campanha e Fronteira Oeste, ambas com $44 \%$ de frequência de detecção, enquanto que na região Sul se constatou menor frequência. Dentre as regiões, a concentração média foi maior na Planície Externa à Laguna dos Patos (23 ng L $\left.{ }^{1}\right)$.

Clomazone possui lixiviação intermediária, contudo, há relatos da ocorrência de clomazone em águas subterrâneas. ${ }^{11}$ Os autores monitoraram clomazone aplicado em lavouras de fumo e detectaram a presença de clomazone em $50 \%$ das amostras de água de poços a jusante das lavouras, e que as concentrações de clomazone se correlacionam com a época de uso mais intenso deste herbicida e, além disso, a pouca cobertura de solo, declividade e intensidade das chuvas contribuem para o aumento do transporte desse herbicida para o ambiente, visto que possui alta solubilidade em água. ${ }^{14}$

O herbicida quinclorac foi detectado apenas na Campanha (11\%) e com concentração média de $60 \mathrm{ng} \mathrm{L}^{-1}$ (Tabela 4). Quinclorac possui um alto potencial de lixiviação no solo, com possibilidade de contaminar águas subterrâneas. No entanto, neste estudo foi o herbicida detectado em menor frequência, possivelmente devido à mobilidade de quinclorac ser dependente das características de solo, como matéria orgânica e da taxa de percolação, ${ }^{14}$ diminuindo à medida que aumenta a CTC, argila e a matéria orgânica do solo. ${ }^{19}$

Imazapic foi detectado em praticamente todas as amostras, com exceção das amostras coletadas na região Fronteira Oeste, sendo que a concentração média foi de $14 \mathrm{ng} \mathrm{L}^{1}$ (Tabela 4). A frequência foi maior na Planície Costeira Interna à Laguna dos Patos e em Santa Catarina, ambas com 33\%. Sob condição de cultivo em arroz inundado, além de não ocorrer a degradação, o herbicida torna-se mais disponível na solução do solo com o aumento do $\mathrm{pH}$ e para outros processos de transporte para águas subterrâneas ou processos de transformação. Isso ocorre, pois em $\mathrm{pH}$ próximos à neutralidade, o grupo funcional ácido carboxílico da molécula de imazapic encontrase na forma dissociada, sendo repelido pelas cargas negativas do solo. Tal comportamento é semelhante aos demais herbicidas do grupo das imidazolinonas. Sendo assim, em solos com textura arenosa, o fluxo de massa pode ser um importante mecanismo de transporte descendente de imazapic. ${ }^{20}$

Já fipronil e imazethapyr foram os agrotóxicos que ocorrem em todas as regiões estudadas, com frequências de 63 a $100 \%$ para fipronil, e 22 a $50 \%$ para imazethapyr (Tabela 4). A meia-vida de fipronil no solo em condições de anaerobiose é de 123 dias, e ainda maior em condições de aerobiose, podendo atingir meia-vida de até 693 dias. ${ }^{21} \mathrm{~A}$ degradação de fipronil pode ocorrer por diferentes processos e originar metabólitos, os quais possuem maior adsorção ao solo, podendo permanecer por mais tempo no ambiente. ${ }^{22}$

As regiões Sul, Planície Costeira Interna e Externa à Laguna dos Patos e Santa Catarina tiveram as concentrações médias para fipronil superiores aos limites propostos pela Comunidade Europeia, com concentração variando de 155 a 910 ng L L . Já para imazethapyr as concentrações médias nas regiões foram abaixo desse valor proposto.

$\mathrm{O}$ fato de imazethapyr ser encontrado em todas as regiões pode ser explicado por suas características físico-químicas, como baixa sorção com o carbono orgânico $\left(\mathrm{K}_{\mathrm{oc}}\right.$ de $\left.53 \mathrm{mg} \mathrm{L}^{-1}\right)$, associado com a alta solubilidade em água (1100 $\left.\mathrm{mg} \mathrm{L}^{-1}\right)$ e a baixa degradação micro-

Tabela 4. Concentrações médias e frequência de agrotóxicos em águas subterrâneas em regiões orizícolas do sul do Brasil na safra 2007/08 na média de três locais de cada região e três épocas de coleta

\begin{tabular}{|c|c|c|c|c|c|c|c|}
\hline \multirow[t]{2}{*}{ Agrotóxicos } & Campanha & $\begin{array}{l}\text { Fronteira } \\
\text { Oeste }\end{array}$ & Sul & $\begin{array}{c}\text { Depressão } \\
\text { Central }\end{array}$ & $\begin{array}{l}\text { Plan. Cost. Interna à } \\
\text { Lag. dos Patos }\end{array}$ & $\begin{array}{l}\text { Plan. Cost. Externa à } \\
\text { Lag. dos Patos }\end{array}$ & $\begin{array}{c}\text { Santa } \\
\text { Catarina }\end{array}$ \\
\hline & \multicolumn{7}{|c|}{ Concentração média detectada $\left.\left(\mathrm{ng} \mathrm{L}^{-1}\right)\right) \pm \mathrm{CV}(\%)^{*}$} \\
\hline Clomazone & $11 \pm 7$ & $5 \pm 12$ & $7 \pm 8$ & nd & nd & $23 \pm 7$ & $<\mathrm{LOQ}$ \\
\hline Imazapic & $<\mathrm{LOQ}^{2}$ & nd & $<\mathrm{LOQ}$ & $<\mathrm{LOQ}$ & 0,014 & $<\mathrm{LOQ}$ & $8 \pm 13$ \\
\hline Imazethapyr & $16 \pm 7$ & $57 \pm 5$ & $<\mathrm{LOQ}$ & $6 \pm 15$ & $26 \pm 8$ & $10 \pm 8$ & $9 \pm 6$ \\
\hline Penoxsulam & $\mathrm{nd}^{1}$ & nd & nd & nd & nd & nd & nd \\
\hline Quinclorac & $60 \pm 7$ & nd & nd & nd & nd & nd & nd \\
\hline 3-hidroxi-carbofuran & nd & nd & nd & nd & nd & nd & nd \\
\hline Carbofuran & nd & nd & nd & nd & nd & nd & nd \\
\hline Fipronil & $11 \pm 7$ & $31 \pm 11$ & $741 \pm 6$ & $22 \pm 7$ & $662 \pm 4$ & $155 \pm 5$ & $910 \pm 3$ \\
\hline \multirow[t]{2}{*}{ Tebuconazole } & nd & nd & nd & nd & nd & nd & nd \\
\hline & \multicolumn{7}{|c|}{ Frequência $(\%)$} \\
\hline Clomazone & 44,4 & 44,4 & 12,5 & nd & nd & 33,3 & 22,2 \\
\hline Imazapic & 11,1 & nd & 25,0 & 11,1 & 33,3 & 22,2 & 33,3 \\
\hline Imazethapyr & 44,4 & 22,2 & 50,0 & 44,4 & 44,4 & 44,4 & 44,4 \\
\hline Penoxsulam & nd & nd & nd & nd & nd & nd & nd \\
\hline Quinclorac & 11,1 & nd & nd & nd & nd & nd & nd \\
\hline 3-hidroxi-carbofuran & nd & nd & nd & nd & nd & nd & nd \\
\hline Carbofuran & nd & nd & nd & nd & nd & nd & nd \\
\hline Fipronil & 77,8 & 88,8 & 63 & 88,8 & 100 & 88,8 & 100 \\
\hline Tebuconazole & nd & nd & nd & nd & nd & nd & nd \\
\hline Ao menos um agrotóxico & 77,8 & 88,8 & 63 & 88,8 & 100 & 88,8 & 100 \\
\hline
\end{tabular}

${ }^{1}$ Não detectado; ${ }^{2}$ Menor que o limite de quantificação; ${ }^{3}$ Metabólito do carbofuran. * Coeficiente de variação percentual (CV \%). 
biana em condições anaeróbicas e, também, a grande área cultivada com o sistema Clearfield ${ }^{\circledR}$, o qual preconiza a utilização de cultivares tolerantes à mistura formulada de imazetapyr e imazapic, além dos fatores discutidos anteriormente para imazapic. Imazethapyr foi o composto com maior frequência de detecção (16\%) em águas superficiais e subterrâneas no Meio-Oeste dos Estados Unidos, seguido de flumetsulam (12\%), nicosulfuron e imazaquin $(8 \%){ }^{23}$

Nas regiões da Planície Costeira Interna à Laguna dos Patos e Santa Catarina pode-se averiguar que a totalidade das amostras monitoradas continha a presença de ao menos um agrotóxico; as regiões da Fronteira Oeste, Depressão Central e Planície Costeira Externa à Laguna dos Patos apresentaram $89 \%$ das amostras contaminadas com agrotóxicos, e as regiões da Campanha e Sul do RS apresentaram 78 e $63 \%$, respectivamente, das amostras contaminadas com ao menos um agrotóxico (Tabela 4). Ainda, do total das amostras monitoradas apenas $11 \%$ não continham a presença destes agrotóxicos monitorados e $27 \%$ das amostras apresentavam concentrações acima do limite proposto pela Comunidade Europeia, sendo que as concentrações acima desse limite foram observadas apenas para o inseticida fipronil.

Todos os agrotóxicos encontrados possuem a tendência de contaminar águas subterrâneas pelos critérios de GUS, embora esse índice desconsidere as características de solo e de práticas de manejo de cada local, que são importantes fatores que influenciam na mobilidade dos agrotóxicos para camadas mais profundas do solo, principalmente em áreas de várzea que são mais planas e nos quais são construídas taipas que fazem a contenção da água para irrigação por inundação, o que favorece a percolação da água e lixiviação dos agrotóxicos dissolvidos. No entanto, o critério GUS é considerado um bom indicador da mobilidade de agrotóxicos, pois a matéria orgânica do solo influencia na sorção, consequentemente, na lixiviação dos agrotóxicos para camadas mais profundas do solo. ${ }^{24}$

A presença desses agrotóxicos em águas subterrâneas pode apresentar problemas com relação à qualidade da água para consumo humano, visto que a tendência é de acúmulo das concentrações desses agrotóxicos ao longo dos anos, podendo causar sérios riscos à saúde humana. Embora encontradas baixas concentrações de agrotóxicos em águas subterrâneas, pouco se sabe dos efeitos adversos do consumo dessa água contaminada, o que demandaria estudos toxicológicos nas concentrações de campo encontradas para se mensurar os possíveis efeitos adversos sobre mamíferos.

Cabe destacar ainda que as legislações brasileiras, normatizadas pela portaria $\mathrm{n}^{\circ} 518$ de 2004 do Ministério da Saúde e pela resolução n 396 de 2008 do CONAMA, não prevêem limites para padrões de potabilidade de águas destinadas ao consumo humano para os agrotóxicos fipronil, clomazone, imazethapyr, imazapic, quinclorac, penoxsulam e tebuconazole, além do metabólito do carbofuran, o 3-hidroxi-carbofuran. Assim, essas legislações deveriam ser revistas para contemplar esses agrotóxicos de ampla utilização na lavoura arrozeira e que estão sendo detectados em amostras ambientais, em águas subterrâneas, como neste trabalho, e em águas superficiais, como em trabalho de outros autores. ${ }^{25}$

\section{CONCLUSÕES}

Em todas as regiões orizícolas do Sul do Brasil verifica-se a presença de ao menos um agrotóxico ocorrente em águas subterrâneas. Fipronil é o agrotóxico detectado em maior número de amostras, seguido de imazethapyr, clomazone, imazapic e quinclorac. Os agrotóxicos penoxsulam, carbofuran, 3-hidroxi-carbofuran e tebuconazole não foram detectados neste estudo. Apenas as concentrações de fipronil ultrapassaram os limites de potabilidade proposto pela Comunidade Europeia, ocorrendo em 27\% das amostras de águas subterrâneas. As concentrações dos agrotóxicos detectados em águas subterrâneas são baixas, sendo necessário realizar trabalhos de análise de risco ambiental desses agrotóxicos nesses níveis de contaminação.

\section{REFERÊNCIAS}

1. http://www.irga.rs.gov.br, acessada em Dezembro 2008.

2. http://www.epagri.sc.gov.br, acessada em Fevereiro 2011.

3. Sociedade Sul-Brasileira de Arroz Irrigado; Arroz irrigado: recomendações técnicas da pesquisa para o Sul do Brasil, Pelotas, Brasil, 2007. CD-ROM.

4. Ribeiro, M. L.; Lourencetti, C.; Pereira, S. Y.; Marchi, M. R. R.; Quim. Nova 2007, 30, 688.

5. Singh, N.; Kloeppel, H.; Klein, W.; Chemosphere 2002, 47, 409.

6. Gustafson, D. I.; Environ. Toxicol. Chem. 1989, 8, 339.

7. Guzzela, L.; Pozzoni, F.; Giuliano, G.; Environ. Pollut. 2006, 142, 344.

8. Tappe, W.; Groeneweg, J.; Jantsch, B.; Biodegradation 2002, 13, 3.

9. EC - European Community; Council Directive 98/83/EC of 1998 on the quality of water intended for human consumption, Official Journal L 330, 05/12/1998, p. 0032-0054. Community legislation in force document 398L0083 (1998).

10. Carbo, L.; Souza, V.; Dores, E. F. G. C.; Ribeiro, M. L.; J. Braz. Chem. Soc. 2008, 19, 1111.

11. Bortoluzzi, E. C.; Rheinheimer, D. S.; Gonçalves, C. S.; Pellegrini, J. B. R.; Maroneze, A. M.; Kurz, M. H. S.; Bacar, N. M.; Zanella, R.; Quim. Nova 2007, 30, 1872.

12. Caldas, S. S.; Demoliner, A.; Primel, E. G.; J. Braz. Chem. Soc. 2009, $20,125$.

13. Demoliner, A.; Caldas, S. S.; Costa, F. P.; Gonçalves, F. F.; Clementin, R. M.; Milani, M. R.; Primel, E. G.; J. Braz. Chem. Soc. 2009, 21, 1424.

14. Senseman, S. A.; Herbicide Handbook, $9^{\text {th }}$ ed., Weed Science Society of America: Lawrence, 2007.

15. Evert, S.; Environmental fate of carbofuran, Environmental Monitoring Branch, Departament of Pesticide Regulation: Sacramento, 2002. http:// www.cdpr.ca.gov/docs/emon/pubs/fatememo/carbofuran.pdf, acessada em Fevereiro 2009.

16. Bobe, A.; Coste, C. M.; Cooper, J. F.; J. Agric. Food Chem. 1997, 45, 4861 .

17. Li, L.; Li, G.; Yang, R.; Guo, Z.; Liao, X.; J. Environmental Sciences 2004, 16, 678.

18. Kyung, K. S.; Suh, Y. T.; Lee, J. K.; Int. J. Environ. Anal. Chem. 1997, $68,187$.

19. Whatley, L. L.; Quinclorac denial of application to register 8/01. 2001, http://pmep.cce.cornell.edu/profiles/herb-growthreg/naarimsulfuron/ quinclorac/quincl_den_0801.html, acessada em Fevereiro 2011.

20. Inoue, M. H.; Oliveira Jr, R. S.; Constantin, J.; Alonso, D. G.; Planta Daninha 2007, 25, 547.

21. Connolly, P.; Environmental fate of fipronil, Califórnia Environmental Protection Agency: Sacremento, 2001, http://www.pw.ucr.edu/textfiles/ fipronil.pdf, acessada em Fevereiro 2009.

22. Ying, G-G.; Kookana, R. S.; J. Environ. Sci. Health, Part B 2001, 36, 545.

23. Battaglin, W. A.; Furlong E. T.; Burkhardt, M. R.; Peter, C. J.; Sci. Total Environ. 2000, 248, 123.

24. Oliveira Jr, R. S.; Koskinen, W. C.; Ferreira, F. A.; Weed Res. 2001, $41,97$.

25. Silva, D. R. O.; Avila, L. A.; Agostinetto, D.; Dal Magro, T.; Oliveira, E.; Zanella, R.; Noldin, J. A.; Cienc. Rural 2009, 39, 2383. 